\title{
CARACTERIZAÇÃO DE ARGAMASSAS HISTÓRICAS: ESTUDO DE CASO DE UMA RESIDÊNCIA LOCALIZADA NA PALMA - MUNICÍPIO DE CAICÓ/RN
}

\section{CHARACTERIZATION OF HISTORICAL MORTARS: CASE STUDY OF A RESIDENCE LOCATED IN PALMA - CAICÓ/RN}

\author{
MEDEIROS, BARAKLEIN \\ Engenheira Civil \\ Universidade Federal Rural do Semi-Árido \\ Rio Grande do Norte; Brasil \\ barakleinmedeiros@gmail.com \\ SALUSTIO, JANAINA \\ Professora \\ Universidade Federal Rural do Semi-Árido \\ Rio Grande do Norte; Brasil \\ janaina.salustio@ufersa.edu.br
}

\author{
BARROS, JOMÁRIO \\ Graduando em Engenharia Civíl \\ Universidade Federal Rural do Semi-Árido \\ Rio Grande do Norte; Brasil \\ jomario108@hotmail.com

\section{SOBRAL, TEREZA} \\ Graduando em Engenharia Civíl \\ Universidade Federal Rural do Semi-Árido \\ Rio Grande do Norte; Brasil \\ tete-olivia@hotmail.com
}

\section{RESUMO}

As edificações antigas são patrimônios que merecem ser preservados para que as futuras gerações tenham acesso as histórias ali antepassadas. Entretanto, para que se possa restaurar e conservar tais edifícios, faz-se necessário conhecer sua forma de construção e os componentes utilizados em sua fabricação, haja vista que o restauro destas, quando feita com materiais não compatíveis, pode resultar em danos irreparáveis. A argamassa de revestimento requer cuidado especial, considerando que a mesma é responsável por revestir e proteger os edifícios contra agentes agressivos. Sabe-se que os revestimentos antigos, na maioria das vezes, eram mais frágeis, tendo em vista que os mesmos eram produzidos a base de cal e areia, e, em alguns casos, com adição de materiais pozolânicos ou orgânicos. Partindo desse pressuposto, este trabalho objetivou caracterizar as argamassas de revestimento de uma residência cuja construção é datada de 1850 , por meio de visitas in loco para estudos visuais, registros fotográficos, realização de croqui e coleta de amostras de diversos pontos da edificação afim de caracterizar a argamassa por meio de análises técnicas e ensaios laboratoriais. Com as amostras foram realizadas análises visuais, ensaio de absorção, ataque químico e ensaio granulométrico. Com os resultados obtidos foi possível determinar a proporção aglomerante:agregado utilizada, sendo observado ainda que foi empregado o mesmo traço em toda a edificação.

Palavras-chave: Construções históricas. Argamassas antigas. Caracterização das argamassas. Cal.

\begin{abstract}
The old buildings are heritage that deserve to be preserved for future generations to have access to the stories there ancestors. However, in order to restore and conserve such buildings, it is necessary to know their construction and the components used in their manufacture, since the restoration of these buildings, when done with non-compatible materials, can result in irreparable damage. Coating mortar requires special care, as it is responsible for coating and protecting buildings against aggressive agents. Old coatings are generally known to be more fragile as they are made from lime and sand, and in some cases with the addition of pozzolanic or organic materials. Based on this assumption, this work aimed to characterize the mortars of a residence whose construction dates from 1850, through on-site visits for visual studies, photographic records, sketching and collection of samples from various points of the building in order to characterize mortar by means of technical analysis and laboratory tests. With the samples were performed visual analysis, absorption test, chemical attack and particle size test. With the obtained results it was possible to determine the agglomerate: aggregate ratio used, and it was observed that the same trait was used throughout the building.
\end{abstract}




\section{INTRODUÇÃO}

As construções antigas espelham de forma física a cultura e a história dos antepassados, sendo mediadora da identidade de cada região, além de manter valores materiais e arquitetônicos para várias gerações. Entretanto, todos os edifícios estão aptos a sofrer com a ação do tempo, a qual, muitas vezes, causam mudanças drásticas em sua formação original (ABREU, 2010).

O Instituto do Patrimônio Histórico e Artístico Nacional (IPHAN) foi criado em 1937 com o intuito de resguardar o importante legado deixado pelas construções históricas, além de fiscalizar e assegurar para que esse patrimônio seja vivenciado pelas futuras gerações.

Todas as construções estão aptas a sofrerem diversas patologias, o fato é que muitas vezes, ao reparar tais danos, não se mantêm a singularidade, propriedades e originalidade do edifício em questão, contudo, para manter todos esses elementos é necessário que se faça um minucioso estudo de caso, bem como a caracterização dos materiais utilizados no local a ser reconstituído.

A caracterização dos materiais, mais precisamente da argamassa, tem como propósito analisar e reconhecer os compostos utilizados na fabricação da argamassa, buscando restabelecer um novo traço capaz de se moldar ao antigo caso seja necessária uma restauração da edificação, mantendo suas propriedades físico-químicas e mecânicas bem como sua forma original (ALMEIDA, 2019).

A argamassa, com seus mais diversos usos na construção civil, já foi produzida com diversos tipos de matéria prima, especialmente materiais locais como o barro, adobe e pedras, e, entre seus usos, destaca-se neste trabalho as argamassas utilizadas para revestir as construções (RODRIGUES, 2013).

O revestimento argamassado tem como importante função proteger e revestir as edificações defendendo-as das ações climáticas e dos inúmeros agentes agressivos. Entretanto, sabe-se que as argamassas antigas eram produzidas de forma a conter muitos poros além de se constituir mais deformáveis.

Lopis (2017) cita que atualmente para manter as memórias dos patrimônios históricos "são criados cenários exóticos que, em muitas ocasiões, chegam à artificialidade, culminando em um preservacionismo cultural de convivência".

Estudar a caracterização das argamassas antigas e originar novos traços capazes de manter todas as vertentes da formação original de cada edifício, deve ser visto não só como um avanço para a comunidade científica, mas como de importante valor para manter a identidade, cultura e história das construções antigas.

Diante do exposto, faz-se necessário o estudo dos materiais utilizados no revestimento de argamassas das antigas construções, esse conhecimento agregará informações acerca da história do edifício, bem como viabilizará a melhor forma de conservação e restauração do mesmo.

\section{METODOLOGIA}

Foi realizado um levantamento acerca dos edifícios que atendessem aos pré-requisitos deste trabalho, onde foi localizada uma residência onde, após uma investigação quanto ao seu ano de construção, se passou ou não por reformar e se a mesma atendia a todas às exigências, obtendo sucesso nos resultados, sucedeu-se visita ao local para obter autorização do responsável para realização do trabalho no local.

\subsection{Local da pesquisa}

O edifício de estudo, visto na figura 1, neste trabalho é considerado patrimônio histórico do Distrito da Palma, município de Caicó no Rio Grande do Norte, a mesma compreende a identidade histórica da região já que traz consigo toda a história antiga daquela sociedade, além do valor artístico e cultural para a mesma. 


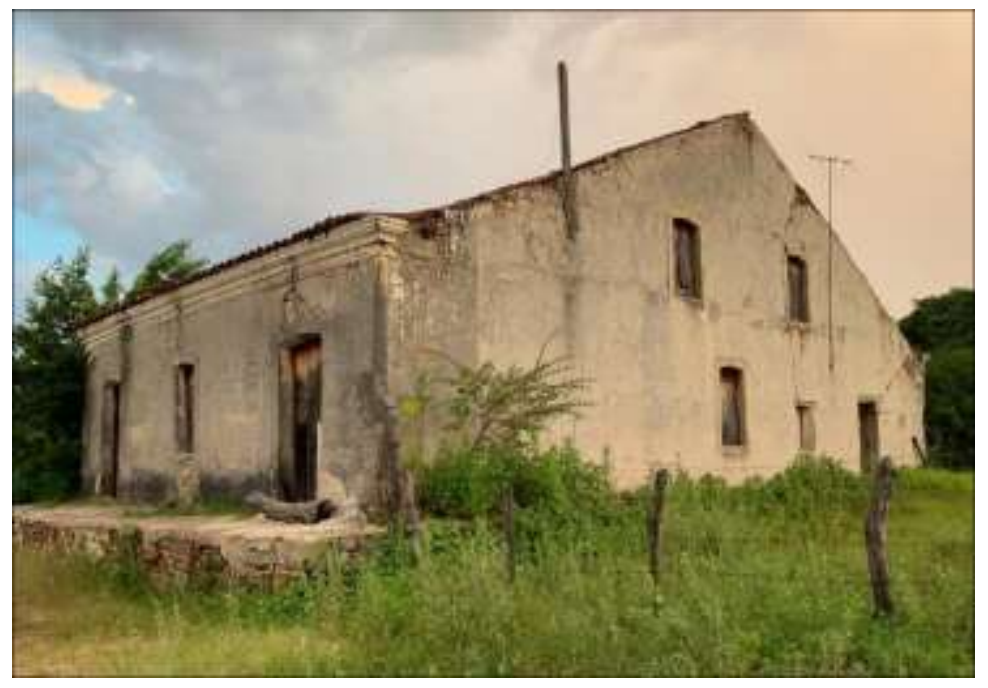

\subsection{Descrição do estudo}

Figura 1: Residência de estudo

Quando autorizado o estudo, transcorreram as coletas, de forma padrão, sendo pré-estabelecida obtenção de amostras nos tamanhos 25 x 25 centímetros e sempre na altura a partir de 1,5 de altura do piso. A medida que iam sendo coletadas, foram identificadas e, posteriormente, fotografados os locais de extração das coletas para melhorar a identificação. Ao fim das coletas, foi realizado um croqui do imóvel, bem como realizadas diversas fotografias, afim de facilitar a realização de uma planta baixa do local, esta vista na figura 2, haja vista que não foram encontradas em nenhum material virtual ou físico.

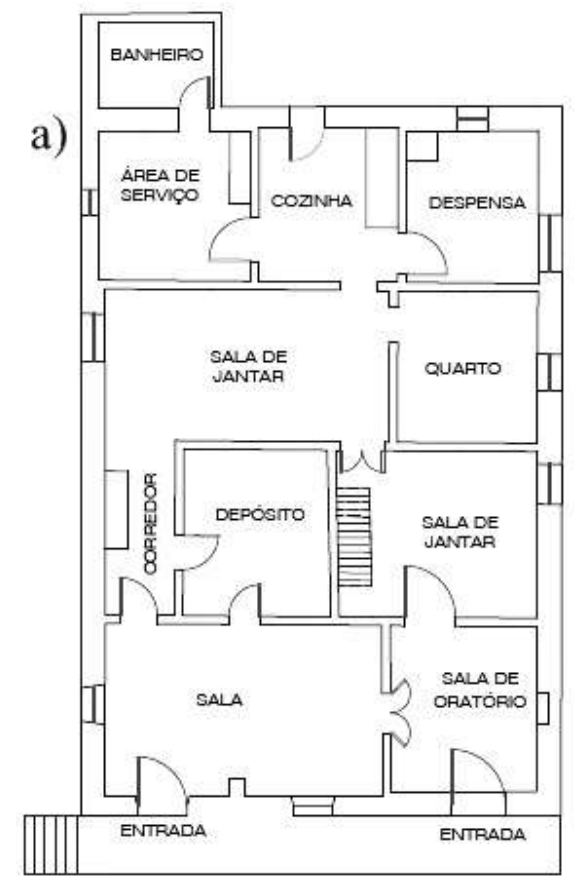

b)

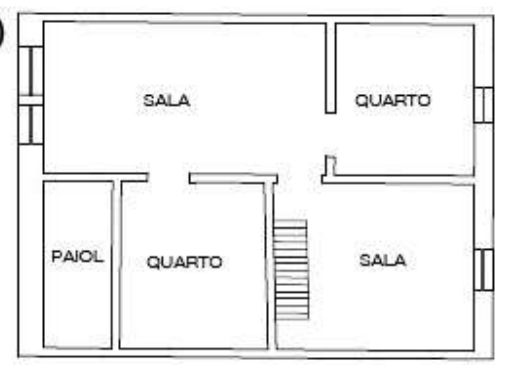

Figura 2: Planta baixa do edifício: a) térreo e b) sótão

Foram realizados os ensaios de: absorção, seguindo a NBR 9778/05 - Argamassa e concreto endurecidos - determinação da absorção de água índice de vazios e massa especifica; granulometria, guiado pela NBR NM 248/03 - Agregados determinação da composição granulométrica; e utilizada a técnica de ataque ácido por meio da incorporação de ácido clorídrico (HCL) em parte das amostras coletadas. 


\subsection{Coleta e preparação das amostras}

As amostras foram classificadas por local, como exposto no Quadro 1, facilitando o rastreamento e consequentemente a comparação de possíveis mudanças de traços conforme os locais de extração.

Quadro 1: Localização das amostras

\begin{tabular}{|c|c|}
\hline IDENTIFICAÇÃO DA AMOSTRA & LOCAL DE EXTRAÇÃO \\
\hline 1 & Parede Interna - Sala de Oratório \\
\hline 2 & Parede Interna - Sala de Jantar \\
\hline 3 & Parede Interna - Cozinha \\
\hline 4 & Parede Interna - Sala de Estar \\
\hline 5 & Parede Externa - Fachada Posterior \\
\hline 6 & Parede Interna - Sala de Jantar \\
\hline 7 & Parede Interna - Sala de Estar \\
\hline 8 & Parede Externa - Fachada Frontal \\
\hline 9 & \\
\hline
\end{tabular}

As películas de tinta de todas as amostras foram removidas de sua superfície com o auxílio de uma lixa, feito isso, as amostras passaram pelo primeiro estudo, o de análise visual, logo após, todas as amostras foram destorroadas individualmente com o auxílio de uma bandeja e um marreta de borracha, com o propósito e cuidado de não prejudicar os elementos a serem estudados.

Após serem destorroadas, as amostras postas em recicientes de vidro e identicadas individualmente, foram levadas para estufa, a uma temperatura média de $100^{\circ} \mathrm{C}$, por 24 horas, passadas as horas, deu-se continuidade aos ensaios propostos.

\section{ENSAIOS}

\subsection{Ataque ácido}

O ataque ácido foi o procedimento escolhido para analisar quimicamente as amostras, sendo ele uma análise por via úmida, já que esta é uma técnica bastante utilizada para diferenciar o aglomerante dos outros componentes solúveis em ácido, principalmente quando se trata de argamassas antigas.

Segundo Kanan (2008), este método de análise é baseado na dissolução dos componentes constituídos de carbonato de cálcio ou magnésio ( $\mathrm{CaCO} 3$ ou $\mathrm{MgCaO} 3$ ) em ácido clorídrico ( $\mathrm{HCl} 14 \%$ ). O aglomerante pode ser encontrado pela diferença de peso total da argamassa menos o peso da areia e dos finos não solúveis no ácido. A equação é descrita a seguir:

$$
2 \mathrm{HCL}+\mathrm{CaCO}_{3}=>\mathrm{CaCl}_{2}+\mathrm{H}_{2} \mathrm{O}+\mathrm{CO}_{2}
$$

Dessa forma, realizou-se esta análise com base nas recomendações de Kanan (2008) bem como na metodologia utilizada no trabalho de Menezes (2019). Para iniciar o ensaio pesou-se 100g de cada amostra, sendo essa a massa inicial, logo após adicionou-se $150 \mathrm{ml}$ de ácido clorídrico (HCL) à 14\% a cada amostra com o auxílio de uma proveta, com ajuda de uma colher de plástico descartável, revolve-se os elementos afim de misturá-los, e deixou o ácido agir por 24 horas. Este processo pode ser visto na Figura 3. 


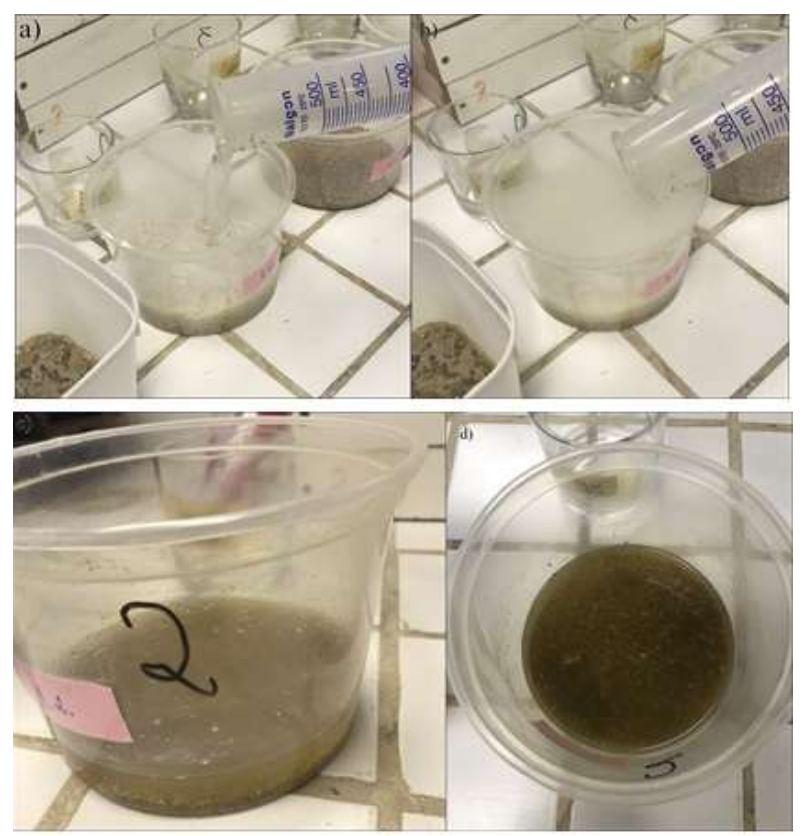

Figura 3:Ataque ácido: a) início da junção do ácido à amostra; b) término da colocação do ácido à amostra; c) amostra após $24 \mathrm{~h}$ de ataque ácido e d) vista superior da amostra após $24 \mathrm{~h}$ de ataque ácido

Após as 24h, as amostras foram drenadas e filtradas com água potável para remoção de todo o ácido, feito isso, as amostras foram levadas novamente a estufa por $24 \mathrm{~h}$ a uma temperatura média de $100^{\circ} \mathrm{C}$ para que decorresse a secagem completa das amostras. Passadas as $24 \mathrm{~h}$, o material foi retirado da estufa e pesados para que se obtivesse o teor de aglomerante no traço de cada amostra de revestimento. O cálculo do teor de aglomerante foi realizado utilizando-se a seguinte equação:

$$
\text { Magl }=m 1-(m 3-m 2)
$$

Equação (1)

Sendo:

Magl: massa de aglomerante (g);

$m 1$ : massa inicial da amostra $(\mathrm{g})$;

$m 2$ : massa do filtro drenante $(\mathrm{g})$;

m3: massa de agregados após secagem e ataque ácido $(\mathrm{g})+$ massa do filtro drenante $(\mathrm{g})$;

\subsection{Análise granulométrica}

Para este ensaio foi utilizado $60 \mathrm{~g}$ de cada amostra, cada uma foi colocada, individualmente, sobre a peneira superior do conjunto, na sequência dita anteriormente, e acionado o agitador mecânico durante 50 segundos por duas vezes consecutivas. Ao fim da agitação a amostra foi separada conforme a classificação das peneiras quanto ao tamanho dos grãos. O material retido em cada peneira foi passado para uma bandeja limpa e pesado posteriormente, para que assim, obtivesse o peso do material retido em cada uma das peneiras e na bandeja de fundo do conjunto. O procedimento pode ser visto na Figura 4. 

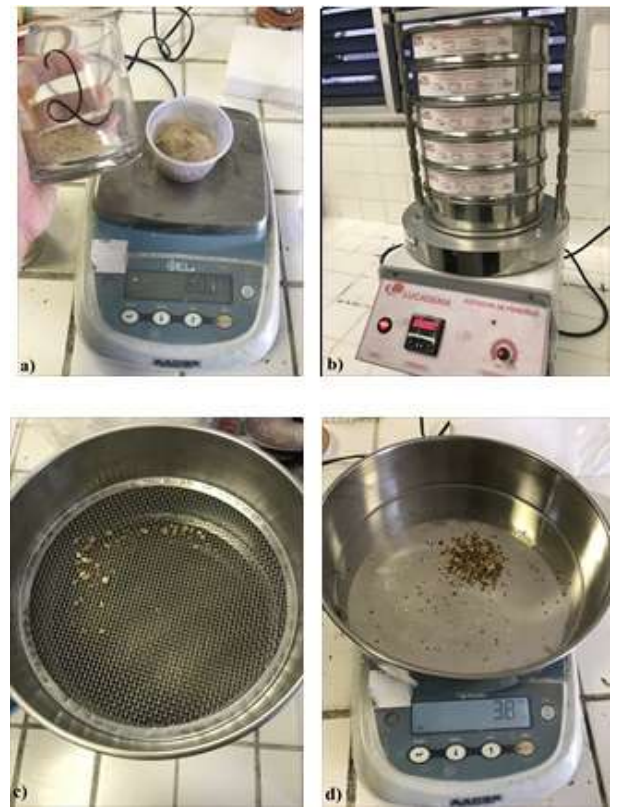

Figura 4: Processo de ensaio de granulometria: a) pesagem de 60g da amostra; b) agitação das peneiras de forma mecânica; c) amostra retida na peneira e d) pesagem do material retido em uma das peneiras

\subsection{Ensaio de absorção}

As amostras passaram pelo processo de retirada de película de tinta com o auxílio de uma lixa, foram identificadas quanto ao seu local de extração e colocadas em estufa para secagem, a uma temperatura média de $100^{\circ} \mathrm{C}$, por 24 horas. Após o processo de secagem, as amostras foram pesadas em balança de precisão de $0,01 \mathrm{~g}$ e posteriormente colocadas imersas em água, como pode ser visualizado na Figura 5. As amostras foram pesadas a cada 24 horas até completar 72 horas de imersão, sendo possível a determinação da sua massa na condição de saturada.

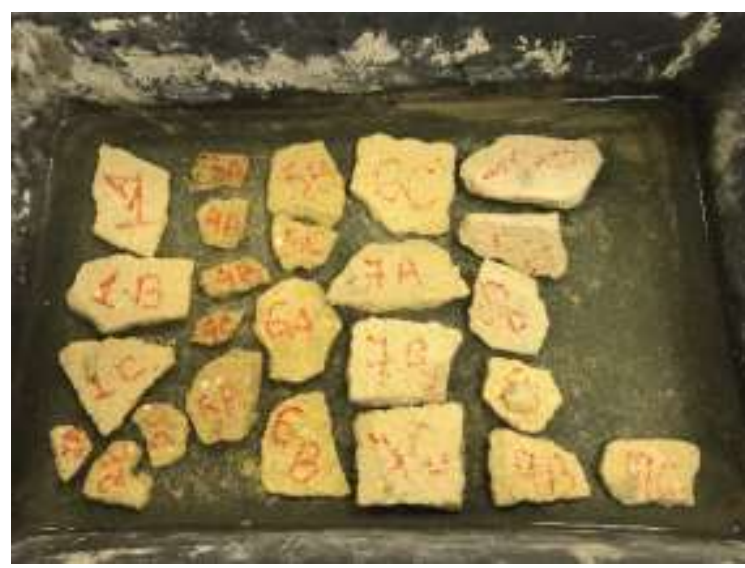

Figura 5: Ensaio de absorção

A taxa de absorção final foi calculada utilizando a equação 4.3:

$$
\text { Absorção }(\%)=\left(\frac{\text { massa final }- \text { massa inicial }}{\text { massa inicial }}\right) \times 100
$$

Equação (2)

Sendo a massa inicial o peso obtido da amostra seca após secagem em estufa, enquanto a massa final é o peso obtido após as 72 horas de imersão da amostra em água. 


\section{RESULTADOS E DISCUSSÕES}

\subsection{Análise visual}

Pôde-se observar que os revestimentos externos possuíam baixa aderência, apresentando facilidade de serem extraídas, muito embora suas espessuras fossem distintas, já que o revestimento da fachada frontal possuía uma camada bem mais grossa que a da fachada posterior. Outra diferença notada entre as duas amostras externas coletadas, foi quanto a sua coloração, já que o revestimento da fachada posterior apresentava coloração levemente mais escura que a da fachada frontal.

Os revestimentos internos, em geral, possuíam boa compacidade/rigidez e boa aderência ao substrato, com exceção da amostra 8 que foi retirada sem o auxílio de marreta. A amostra 3 apresentou maior dificuldade de ser extraída, a parede apresentava coloração preta, acredita-se que tenha sido devido a queima de alimentos, já que a mesma acoplava um fogão a lenha.

Vale ressaltar que a presença de nódulos de carbonatos de cálcio foi notória em todas as amostras.

\subsection{Análise química por meio do ataque ácido}

A Tabela 1 denota a relação aglomerante:agregado em massa (g) identificadas através da análise química.

Tabela 1: Relação de aglomerante/agregado em massa (g) e estimativa de traço da argamassa estudada

\begin{tabular}{c|c|c|c|c}
\hline Amostra & $\begin{array}{c}\text { Aglomerante } \\
(\mathbf{g})\end{array}$ & $\begin{array}{c}\text { Agregado } \\
(\mathbf{g})\end{array}$ & $\begin{array}{c}\text { Aglomerante:Agregado } \\
\text { Traço } \\
\text { Equivalente }\end{array}$ \\
\hline 1 & 11,3 & 88,7 & 7,8 & $1: 8$ \\
\hline 2 & 10,9 & 89,1 & 8,2 & $1: 8$ \\
\hline 3 & 12,5 & 87,5 & 7,0 & $1: 7$ \\
\hline 4 & 11,6 & 88,4 & 7,6 & $1: 8$ \\
\hline 5 & 10,7 & 89,3 & 8,3 & $1: 8$ \\
\hline 6 & 11,1 & 88,9 & 8,0 & $1: 8$ \\
\hline 7 & 11,3 & 88,7 & 7,8 & $1: 8$ \\
\hline 8 & 10,9 & 89,1 & 8,2 & $1: 8$ \\
\hline
\end{tabular}

Os resultados obtidos e demonstrados na tabela anterior mostram que, das 9 amostras analisadas, foram aferidos dois tipos de traços, consistindo em 1:7 e 1:8, este último sendo o mais empregado. As proporções encontradas de aglomerante: agregado, também foram semelhantes as observadas por Almeida (2018) e Menezes (2019).

O único traço com variação considerável foi a amostra 3, onde, como já foi descrito, a mesma foi retirada de uma parede com presença de queimaduras, que acoplava um fogão a lenha, como pode ser visualizado na Figura 23.

A argamassa de revestimento vinha sofrendo queimaduras nessa região, liberando e concentrando gás carbônico, logo, pode-se ter resultando numa maior formação de carbonato de cálcio. A cal hidratada é rica em hidróxidos de cálcio e, quando passa pelo processo de endurecimento, a argamassa de cal endurece sob a reação do hidróxido de cálcio com o gás carbônico, formando o carbonato de cálcio. Como a concentração de gás carbônico nessa área era maior devido a queima do forno a lenha, pode ter havido uma maior produção e reação química do carbonato de cálcio quando comparado as demais regiões de coleta. Esse fator pode explicar uma pequena quantidade levemente superior de aglomerante no traço deste cômodo.

Outro fator que pode explicar essa alteração é a falta de controle tecnológico na produção da argamassa da época, onde pode ter havido uma mudança de padrão quanto as dosagens de materiais utilizados para sua fabricação.

\subsection{Ensaio de granulometria}


A Tabela 2, mostra o resultado da porcentagem passante nas peneiras das amostras que foram usadas no ensaio granulométrico, pôde-se observar que o agregado miúdo constitui maior parte das amostras, como disposto na NBR 7211 (ABNT, 2009), onde os grãos passam pela peneira com abertura de 4,75mm. Entretanto, nas amostras 2, 6 e 7, uma pequena massa ficou retida na peneira de malha $4,75 \mathrm{~mm}$, cerca de $0,3 \mathrm{~g}$, logo, essas amostras compõem de agregados miúdos com a presença de pequenos pedriscos.

Tabela 2:Porcentagem do material passante nas peneiras

\begin{tabular}{c|c|c|c|c|c|c|c|c|c}
\hline \multirow{2}{*}{$\begin{array}{c}\text { Abertura } \\
\text { das } \\
\begin{array}{c}\text { Peneiras } \\
(\mathbf{m m})\end{array}\end{array}$} & $\mathbf{1}$ & $\mathbf{2}$ & $\mathbf{3}$ & $\mathbf{4}$ & $\mathbf{5}$ & $\mathbf{6}$ & $\mathbf{7}$ & $\mathbf{8}$ & $\mathbf{9}$ \\
\cline { 2 - 10 } & \multicolumn{7}{|c|}{ Retido acumulado (\%) } \\
\hline $\mathbf{4 , 7 5}$ & 0,0 & 0,5 & 0,0 & 0,0 & 0,0 & 0,3 & 0,5 & 0,0 & 0,0 \\
\hline $\mathbf{2 , 3 6}$ & 1,8 & 6,5 & 4,7 & 4,5 & 3,2 & 3,3 & 10,9 & 0,5 & 3,5 \\
\hline $\mathbf{1 , 1 8}$ & 7,7 & 16,3 & 19,8 & 17,1 & 12,5 & 14,7 & 28,2 & 3,7 & 13,7 \\
\hline $\mathbf{0 , 6}$ & 29,5 & 40,9 & 51,3 & 47,8 & 38,2 & 43,4 & 62,6 & 19,9 & 42,3 \\
\hline $\mathbf{0 , 3}$ & 61,7 & 77,4 & 83,5 & 80,4 & 74,5 & 78,6 & 88,8 & 65,3 & 79,3 \\
\hline $\mathbf{0 , 1 5}$ & 83,0 & 95,5 & 96,5 & 95,3 & 93,3 & 95,5 & 97,8 & 90,3 & 95,8 \\
\hline $\mathbf{F u n d o}$ & 100 & 100 & 100 & 100 & 100 & 100 & 100 & 100 & 100 \\
\hline
\end{tabular}

A Figura 6, mostra o gráfico formado por meio do cruzamento das curvas granulométricas resultantes dos dados obtidos através da porcentagem retida acumulada e das aberturas das malhas das peneiras.

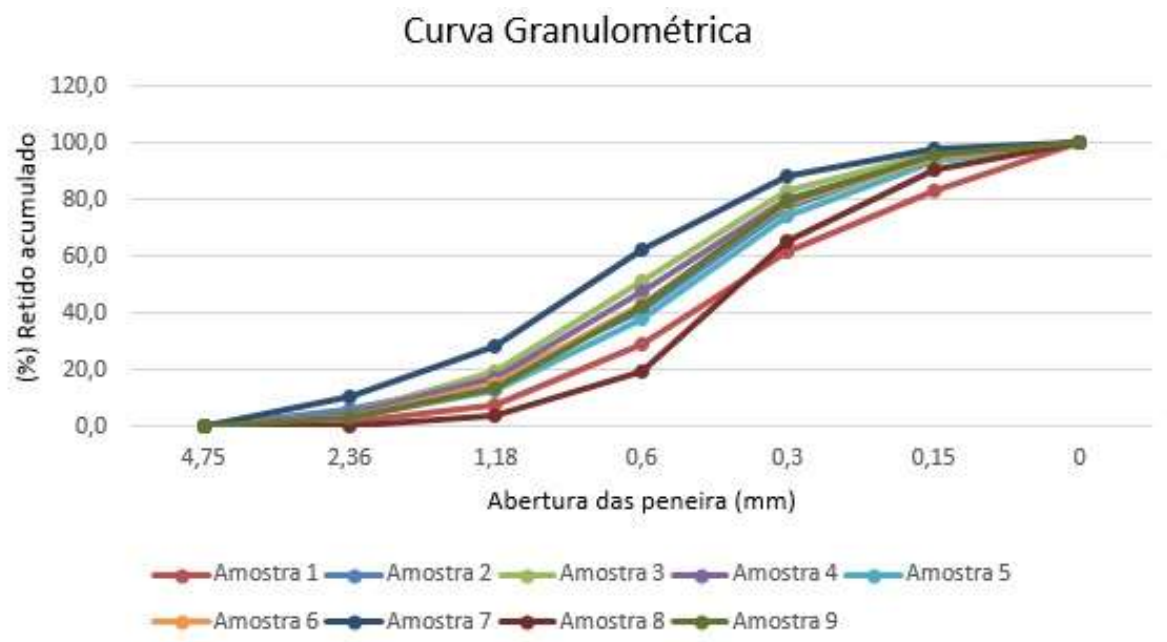

Figura 6: Curvas granulométricas dos agregados da amostras coletadas

De acordo com resultados obtidos, podemos observar que a maior parte das amostras ficaram retidas na peneira de abertura $0,3 \mathrm{~mm}$ e passaram na peneira de abertura $0,6 \mathrm{~mm}$, o que sugere uso de areia média, além disso, ao analisar a curva pode-se atribuir a areia uma boa graduação uma vez que se tem material de todos os tamanhos retidos em todas as peneiras utilizadas. A partir da curva é possível observar ainda o comportamento semelhante entre os agregados das diferentes amostras, isso demonstra que os agregados utilizados para confecção destas argamassas podem ter tido a mesma procedência.

Ainda segundo a NBR 7211(ABNT, 2009), foram calculados os módulos de finura de cada amostra, bem como seus diâmetros máximos. Os resultados obtidos podem ser vistos na Tabela 3. As conclusões foram que a maioria das amostras, sendo elas: 2, 3, 4, 5, 6, 7 e 9, se enquadram no módulo de finura da zona ótima, que deve variar entre 2,20 a 2,90 ficando 
então enquadrados como areia de granulometria média. Enquanto as amostras 1 e 8 se enquadram no módulo de finura da zona utilizável inferior, que varia entre 1,55 e 2,20 e recebe a classificação de areia fina.

Tabela 3: Propriedades físicas do agregado

\begin{tabular}{c|c|c|c|c|c|c|c|c|c}
\hline Amostras & 1 & 2 & 3 & 4 & 5 & 6 & 7 & 8 & 9 \\
\hline M. F. & 1,84 & 2,37 & 2,56 & 2,45 & 2,22 & 2,36 & 2,89 & 1,80 & 2,35 \\
\hline Dmáx (mm) & 2,36 & 4,75 & 2,36 & 2,36 & 2,36 & 2,36 & 4,75 & 1,18 & 2,36 \\
\hline
\end{tabular}

Sobre os diâmetros máximos, podemos observar que, na maioria das amostras $(1,3,4,5,6$ e 9), é de 2,36mm, sendo apenas duas (2 e 7), com diâmetro máximo de 4,75 e uma (8) com 1,18mm. Observa-se então que existe uma pequena variação entre as amostras, já que o Dmáx predominante é de 2,36mm.

\subsection{Ensaio de absorção}

A Figura 7 apresenta as médias de absorção de cada amostra ensaiada, bem como o desvio padrão indicado em cada uma das amostras, tendo seus valores descritos na Tabela 4.

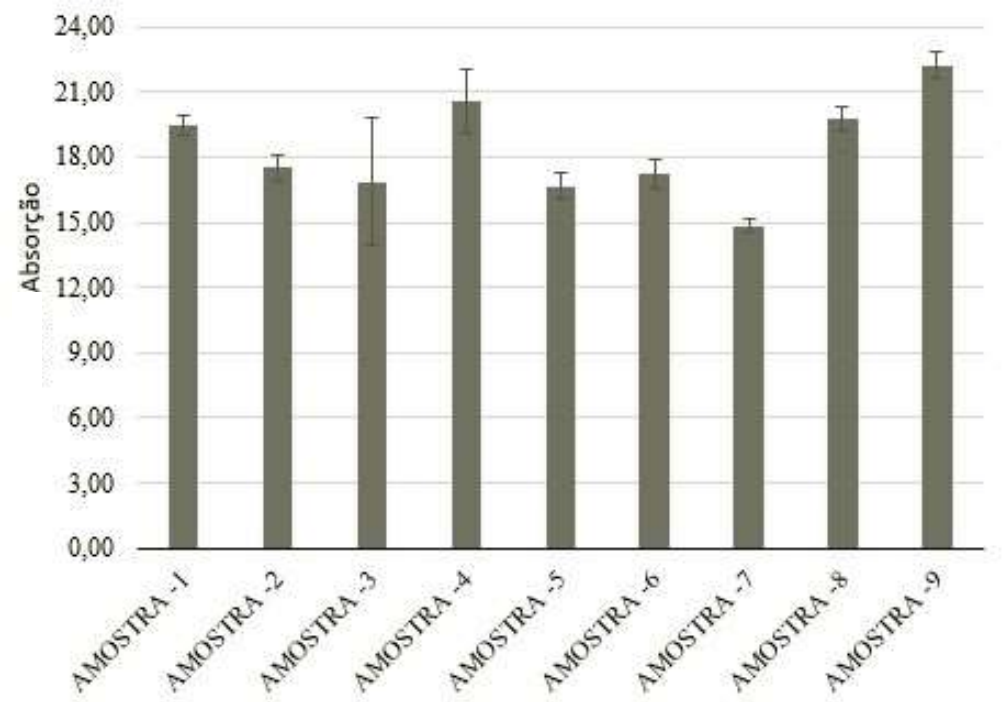

Figura 7: Absorção das amostras

Tabela 4:Desvio Padrão e taxa de abs. das amostras

\begin{tabular}{c|c|c|c|c|c|c|c|c|c}
\hline Amostras & 1 & 2 & 3 & 4 & 5 & 6 & 7 & 8 & 9 \\
\hline Taxa de Abs. & 19,47 & 17,48 & 16,87 & 20,56 & 16,66 & 17,23 & 14,84 & 19,77 & 22,23 \\
\hline Desvio Padrão & 0,43 & 0,65 & 2,96 & 1,44 & 0,62 & 0,70 & 0,28 & 0,59 & 0,61 \\
\hline
\end{tabular}

Pôde-se observar que a amostra 9 apresentou maior taxa de absorção, com resultado superior a 22\%, trata-se da amostra retirada do revestimento da fachada frontal da edificação, enquanto a amostra 7 exibiu o a menor taxa de absorção com $14,84 \%$, sendo essa amostra referente a um revestimento de parede interna. O desvio padrão calculado das amostras em geral resultou em 2,31 .

Ao se comparar com taxas de absorção de argamassas cimentícias pode-se observar que as argamassas a base de cal são bem mais porosas, tendo taxas aproximadamente $35 \%$ superior.

\section{CONSIDERAÇÕES FINAIS}


O presente trabalho objetivou caracterizar as argamassas de uma casa considerada patrimônio histórico da Palma, município de Caicó no Rio Grande do Note, além de agregar conhecimentos quanto aos materiais utilizados nas argamassas antigas da região do Rio Grande do Norte.

Diante dos resultados expostos e referenciados, pode-se fazer as seguintes conclusões:

- Todas as amostras extraídas eram parecidas quanto a sua coloração e porosidade, e apresentavam nódulos de carbonato de cálcio; as amostras internas demonstraram ser mais resistentes e possuir maior aderência ao substrato que as externas na hora da extração.

- As amostras 1 e 9 tiveram comportamento quebradiço, tanto no manuseio, quanto em contato com a água no ensaio de absorção, tal fator pode ser explicado devido a presença de argila aparente nessas duas amostras.

- Foram encontrados apenas dois traços distintos de argamassas utilizadas à base de cal, onde a amostra 3, que apresentou traço distinto dos demais, pode ter tido seus resultados alterados devido a quantidade de calor recebida ao longo dos anos.

- Através do ensaio de granulometria podemos concluir que as amostras 2, 3, 4, 5, 6, 7 e 9, se enquadram no módulo de finura da zona ótima, que deve variar entre 2,20 a 2,90, sendo assim agregados referentes a areia média. Enquanto as amostras 1 e 8 se enquadram no módulo de finura da zona utilizável inferior, que varia entre 1,55 e 2,20, sendo elas referentes a areia fina.

- No que diz respeito ao diâmetro, constatou-se uma variância muito pequena, haja vista que 6 das 9 amostras apresentaram Dmáx como sendo 2,36mm.

- No ensaio de absorção as amostras apresentaram taxas altas de absorção, o que já era de se esperar, uma vez que se trata de argamassas a base de cal aérea, que gera um material mais poroso visto que não há a presença de materiais cimentantes para promover o refinamento da estrutura porosa do material.

Os resultados e conclusões expostos nos provaram que, de fato, a edificação estudada foi construída como sendo o seu aglomerante a cal, e que, embora se trate de uma edificação antiga, não houve muitas diferenças quanto ao controle tecnológico dos materiais utilizados nos cômodos da edificação.

Para trabalhos futuros, sugere-se que sejam estudados, além dos materiais e componentes utilizados nas argamassas, as patologias presentes no edifício, afim que se possa ter um resultado ainda mais complexo quanto a interferência dessas patologias nos resultados obtidos das amostras colhidas.

\section{REFERÊNCIAS}

ABCP. Associação Brasileira de Cimento Portland. Manual de revestimentos de argamassa. 2002. Disponível em: <http://www.comunidadedaconstrucao.com.br/upload/ativos/279/anexo/ativosmanu.pdf>. Acesso em: 08 de junho de 2019.

ABREU, Luciana Barbosa. ENSAIOS NÃO DESTRUTIVOS PARA AVALIAÇÃO DA INTEGRIDADE DE ELEMENTOS ESTRUTURAIS DE MADEIRA EM CONSTRUÇÕES HISTÓRICAS. 2010. 146 f. Tese (Doutorado) - Ciência e Tecnologia da Madeira, UFLA, Lavras, 2010.

AMBROZEWICZ, Paulo H. L. Materiais de Construção: Normas, Especificações, Aplicações e Ensaios de Laboratório. $1^{a}$ Edição. São Paulo: PINI, 2012. 460 p

ALMEIDA, José Carlos Gomes de. CARACTERIZAÇÃo DE ARGAMASSAS HISTÓRICAS: ESTUDO DE CASO DO MERCADO PÚBLICO DE JARDIM DE PIRANHAS/RN. 2019. 51 f. TCC (Graduação) - Curso de Engenharia Civil, UFERSA, Angicos, 2019.

ALMEIDA, Luís Filipe dos Santos de. CARACTERIZAÇÃO DAS ARGAMASSAS DA MURALHA TARDO ROMANA DE OLISIPO. 2015. 194 f. Dissertação (Mestrado) - Curso de Mestrado em Geologia Aplicada, Departamento de Geologia, Universidade de Lisboa, Lisboa - Portugal, 2015. 
ALVAREZ, José Antônio Sequeira. Alvenarias e argamassas anteriores ao Império Romano. $2^{\circ}$ Congresso Nacional de Argamassas de Construção. 2007. APFAC, Lisboa.

ALVAREZ, José; SEQUEIRA, Cristina; COSTA, Marta. Ensinamentos a retirar do Passado Histórico das Argamassas. Apresentado em: $1^{\circ}$ Congresso Nacional de Argamassas de Construção, Lisboa - Portugal 2005.

ANTUNES, R. P. N., 2005. Influência da reologia e da energia de impacto naresistência de aderência de revestimentos de argamassa. Tese de D. Sc.,Escola Politécnica da Universidade de São Paulo, São Paulo

ASSOCIAÇÃO BRASILEIRA DE NORMAS TÉCNICAS. ABNT. NBR 7211. Agregados para Concreto Especificação. Rio de Janeiro, 2009.

ASSOCIAÇÃO BRASILEIRA DE NORMAS TÉCNICAS. ABNT. NBR 13529. Revestimento de Paredes e Tetos de Argamassas Inorgânicas - Terminologia. Rio de Janeiro, 2013.

ASSOCIAÇÃO BRASILEIRA DE NORMAS TÉCNICAS. NBR NM 248: - AGREGADOS - DETERMINAÇÃO DA COMPOSIÇÃO GRANULOMÉTRICA. Rio de Janeiro: ABNT, 2003. 13 p.

ASSOCIAÇÃO BRASILEIRA DE NORMAS TÉCNICAS. NBR 9778: ARGAMASSA E CONCRETO ENDURECIDOS - DETERMINAÇÃO DA ABSORÇÃO DE ÁGUA ÍNDICE DE VAZIOS E MASSA ESPECÍFICA. Rio de Janeiro: ABNT, 2005. 8 p.

Barbosa, Rui - Notas de Aula da disciplina de Materiais de Construção Civil II - Centro Universitário da FEI, 2015.

Brown, David J. Bridges, Reed International Books, London, 1993

CARASEK, H. Argamassa. In: Isaia, G. C. (org). Materiais de Construção e Princípios de Ciência e Engenharia de Materiais. São Paulo: IBRACON, v.2, cap 26, p. 863-903, 2007.

CINTRA, Cynthia Leonis Dias. Argamassa para revestimento com propriedades termo acústicas, produzida a partir de vermiculita expandida e borracha reciclada de pneus. 2013. 186f. Curso de Engenharia de Materiais, Universidade Federal de São Carlos, São Carlos, 2013.

COUTINHO, J. (2006) - Materiais de Construção 2: $1^{\text {a }}$ Parte-Ligantes e Caldas.Faculdade de Engenharia da Universidade do Porto.

FARIA, P.(2004) -Argamassas de revestimento para alvenarias antigas. Contribuição para o estudo da influência dos ligantes. Tese de Doutoramento em Engenharia Civil -Reabilitação do Património Edificado, Universidade Nova de Lisboa.

FIORITO, Antônio J.S.I. Manual de Argamassas e revestimentos: estudos eprocedimentos de execução. São Paulo, Pini, 2004.

FONSECA, Vanessa Rafaela de Sousa. Estudo das Principais Argamassas Utilizadas na Reabilitação de Edifícios Antigos. 2016. 176 f. Dissertação (Mestrado) - Instituto Superior de Engenharia do Porto.

HUGHES, John $\mathrm{j}$. The role of mortar in masonry: an introduction to requirements for the design of repair mortars. Materials and Structures: RILEM TC 203-RHM: Repair mortars for historic masonry: Scotland, UK, 2012.

LOPIS, Erivania Azevedo. Patrimônio histórico cultural: preservar ou transformar? Uma questão conflituosa. 2017. 15 f. Dissertação (Mestrado) - Curso de História Social da Cultura Regional, UFRPE, Pernambuco, 2017.

KANAN, Maria. Isabel. Manual de Conservação e Intervenção em Argamassas e Revestimentos a Base de Cal. Cadernos Técnicos 8. IPHAN/Programa Monumenta, Brasília, 2008.

MARgalHA, M. Argamassas: document de apoio às aulas de Conservação e Recuperação do Patrimônio. 2011. Universidade de Évora. Portugal. 
MALINOWSKI, R.-R. Ancient mortars and concrets: Aspects of their durability, in Histoire of Technology, 7th Annual Volume, Mansell U.K., 1991.

MARQUES, S. M. F. Estudo de Argamassas de Reabilitação de Edifícios Antigos. 2005. 148f. Dissertação Mestrado - Universidade de Aveiro, Portugal.

MENEZES, A.L.R de. Caracterização de argamassas históricas existentes na Usina de Ilha Bela localizada no município de Ceará Mirim/RN. 2019. 96f. Dissertação do Programa de Pós Graduação em Engenharia Civil. Universidade Federal do Rio Grande do Norte.

Moropoulou, A.; Bakolas, A.; Anagnostopoulou, S.; “Composite materials in ancient structures", Cement and Concrete Composites 27 (2005), pp 295-300

RECENA, Fernando Antônio Piazza. Conhecendo argamassa. 1ª ed. EDIPUCRS. Porto Alegre/RS, 2007.

RODRIGUES, Paula Nader. CARACTERIZAÇÃO DAS ARGAMASSAS HISTÓRICAS DA RUÍNA DE SÃO MIGUEL ARCANJOS/RS. 2013. 142 f. - Dissertação (Mestrado) - Engenharia Civil, UFSM, Santa Maria/RS, 2013.

ROSA, Paulo Jorge Pereira da. Caracterização de Argamassas Históricas do Convento de Cristo - Tomar. 2016.216 f. Dissertação (Mestrado) - Curso de Química, Universidade de Lisboa, Campo Grande, 2016.

SABBAtini, F. H. Argamassas de Assentamento para Paredes de Alvenaria Resistente. Boletim técnico 02/86. Escola Politécnica da Universidade de São Paulo. São Paulo, 1986.

SOUSA, Adla Kellen Dionisio. ARGAMASSAS DO GRUPO ESCOLAR AUGUSTO SEVERO/RN: CARACTERIZAÇÃo E INCIDÊNCIA DE MANIFESTAÇÕES PATOLÓgICAS. 2014. 142f. - Curso de Pós Graduação em Engenharia Civil, Universidade Federal do Rio Grande do Norte, Natal, 2014.

SOUSA, Thamyres de Medeiros. Análise das Propriedades Mecânicas de Argamassas com Adição de Vidro Triturado. 2016. 41 f. Graduação em Engenharia Civil. Universidade Estadual da Paraíba. Araruna/PB. 2016.

TORGAL, Fernando Pacheo; JALALI, Said. A Sustentabilidade dos Materiais de Construção. 2010. 460 f. Guimarães, Portugal. 2014. 